\title{
Organic nutrients and excess nitrogen in the North Atlantic subtropical gyre
}

\author{
A. Landolfi ${ }^{1}$, A. Oschlies ${ }^{1}$, and R. Sanders ${ }^{2}$ \\ ${ }^{1}$ IFM-GEOMAR, Leibniz-Institut für Meereswissenschaften, Dusternbrooker Weg 20, 24105 Kiel, Germany \\ ${ }^{2}$ National Oceanography Centre, Southampton University, European way, SO14 3ZH, Southampton, UK
}

Received: 11 December 2007 - Published in Biogeosciences Discuss.: 14 February 2008

Revised: 29 July 2008 - Accepted: 8 August 2008 - Published: 1 September 2008

\begin{abstract}
To enable an accurate estimate of total excess nitrogen $(\mathrm{N})$ in the North Atlantic, a new tracer TNxs is defined, which includes the contribution of organic nutrients to the assessment of $\mathrm{N}: \mathrm{P}$ stoichiometric anomalies. We measured the spatial distribution of TNxs within the subtropical North Atlantic using data from a trans-Atlantic section across $24.5^{\circ} \mathrm{N}$ occupied in 2004. We then employ three different approaches to infer rates of total excess nitrogen accumulation using pCFC-12 derived ventilation ages (a TNxs vertical integration, a one end-member and a two-end member mixing model). Despite some variability among the different methods the dissolved organic nutrient fraction always contributes to about half of the TNxs accumulation, which is in the order of $9.38 \pm 4.18 \times 10^{11} \mathrm{~mol} \mathrm{Ny}^{-1}$. We suggest that neglecting organic nutrients in stoichiometric balances of the marine $\mathrm{N}$ and $\mathrm{P}$ inventories can lead to systematic errors when estimating deviations of nitrogen excess or deficit relative to the Redfield ratio in the oceans. For the North Atlantic the inclusion of the organic fraction to the excess nitrogen pool leads to an upward revision of the $\mathrm{N}$ supply by $\mathrm{N}_{2}$ fixation to $10.2 \pm 6.9 \times 10^{11} \mathrm{~mol} \mathrm{Ny}^{-1}$.
\end{abstract}

\section{Introduction}

The oceans contain the largest pool of carbon on the planet accessible on time scales shorter than a millennium and are implicated in the regulation of atmospheric $\mathrm{CO}_{2}$ through the temperature dependent solubility of $\mathrm{CO}_{2}$ in seawater (the solubility pump) and the sinking of organic matter from the productive surface layers to the deep ocean (the biological pump). Outside the high-nutrient, low-chlorophyll regions where iron is known to limit primary productivity, the

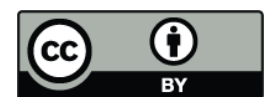

Correspondence to: A. Landolfi (alandolfi@ifm-geomar.de) strength of the biological carbon pump is strongly controlled by the bioavailability of macro-nutrients, namely fixed nitrogen $(\mathrm{N})$ and phosphorus $(\mathrm{P})$ in the sunlit surface ocean. Hence, quantifying the processes that control the fluxes of $\mathrm{N}$ and $\mathrm{P}$ into the oceans and to surface waters, where they sustain phytoplankton growth, is important for assessing the role of marine biology in the global carbon cycle. One critical area where such efforts are required is the subtropical gyres. These extensive areas are estimated to account for half of the global export of organic carbon from the surface to the deep ocean (Emerson et al., 2001). In the North Atlantic gyre diffusive nitrate supply to surface layers (Ledwell et al., 1993) is too low to explain the oxygen consumption in deep layers (Jenkins, 1988; Jenkins and Goldman, 1985). Efforts have been made recently to investigate alternative nutrient supply through physical processes (McGillicuddy et al., 1998; Dietze et al., 2004), atmospheric deposition (Prospero et al., 1996) and nitrogen fixation (Gruber and Sarmiento, 1997; Hansell et al., 2004; Capone et al., 2005; Hansell et al., 2007). Large uncertainties exist in $\mathrm{N}_{2}$ fixation estimates of the North Atlantic. Historically a significant offset between direct measurements and indirect geochemical estimates, attributed to the different spatial and temporal scales of the two methodologies, was observed. However, recent direct observations of high $\mathrm{N}_{2}$ fixation rates (Capone et al., 2005) are more consistent with earlier indirect geochemical estimates. On the contrary, new North Atlantic geochemical $\mathrm{N}_{2}$ fixation estimates have been revisited downwards (Hansell et al., 2004; Hansell et al., 2007).

Geochemical estimates of the large scale distribution and rate of $\mathrm{N}_{2}$ fixation have been based upon $\mathrm{NO}_{3}^{-}$to $\mathrm{PO}_{4}^{3-}$ ratio anomalies (Gruber and Sarmiento, 1997; Hansell et al., 2004; Michaels et al., 1996; Deutsch et al., 2001) (hereafter referred to as M96, GS97, D01 and H04) as compared to the Redfield stoichiometry (16:1) (Redfield et al., 1963) which is assumed to reflect the average $\mathrm{N}$ and $\mathrm{P}$ composition of marine phytoplankton. M96 first introduced

Published by Copernicus Publications on behalf of the European Geosciences Union. 
the concept of the quasi-conservative geochemical tracer $\mathrm{N}^{*}=\left[\mathrm{NO}_{3}^{-}\right]-16^{*}\left[\mathrm{PO}_{4}^{3-}\right]+2.7 \mathrm{mmol} \mathrm{m}{ }^{-3}$, which traces the production or consumption of nitrate, with a $\mathrm{N}: \mathrm{P}$ stoichiometry different from the canonical $16: 1$. The definition of $\mathrm{N}^{*}$ has undergone minor modifications by other authors (GS97, D01) and evolved into the concept of excess inorganic nitrogen (DINxs $\left.=\left[\mathrm{NO}_{3}^{-}\right]-16^{*}\left[\mathrm{PO}_{4}^{3-}\right] ; \mathrm{H} 04\right)$. Despite the various parameterizations, $\mathrm{N}^{*}$ and DINxs represent the deviation from the 16:1 nutrient ratio and reflect the impact of processes that add or remove $\mathrm{NO}_{3}^{-}$or $\mathrm{PO}_{4}^{3-}$ with a N:P stoichiometry different from 16:1. Previous geochemical estimates assumed $\mathrm{N}_{2}$ fixation and denitrification to be the only relevant processes able to alter the Redfield stoichiometry; corrections accounting for the contribution of atmospheric deposition have been applied a-posteriori (GS97). Using this technique, an excess of nitrate over phosphate has been reported for the North Atlantic thermocline waters and $\mathrm{N}_{2}$ fixation has been invoked to explain such stoichiometric anomalies, based on the assumption that $\mathrm{N}_{2}$ fixing organisms have a non-Redfield stoichiometry of $\mathrm{N}: \mathrm{P}=125$ (Karl et al., 1992). However, GS97 and Karl et al. (2002) both suggested that the lack of knowledge of the organic fractions of the $\mathrm{N}$ and $\mathrm{P}$ pools, total organic nitrogen (TON) and total organic phosphorus (TOP), does not allow to quantify the sizes of the total inventories of $\mathrm{N}$ and $\mathrm{P}$ and thus the deviations of their stoichiometric ratios. For example, previous geochemical estimates neglect the contribution of processes such as any preferential remineralization of TOP at the surface and the subsequent remineralization of $\mathrm{N}$ rich sinking organic matter at depth, or the selective uptake of $\mathrm{PO}_{4}^{3-}$ w.r.t. $\mathrm{NO}_{3}^{-}$. These processes may cause DINxs anomalies but will not affect the total inventories of $\mathrm{N}$ and $\mathrm{P}$, thus leading to erroneous excess $\mathrm{N}$ estimates. Similarly, $\mathrm{N}$ fixed by diazotrophs may enter the organic nutrient pool and hence may not be accounted for in the local DINxs signal. A major fraction of the nutrient pool of the surface oceans consists of DON and DOP (Jackson and Williams, 1985) and up to half of the recently fixed nitrogen has been observed to be released as DON (Glibert and Bronk, 1994; Mulholland et al., 2004; Capone et al., 1994). Thus neglecting the organic nutrient pools when assessing the deviations of stoichiometric balances may adversely affect our interpretation of the oceanic processes that involve $\mathrm{N}$ and $\mathrm{P}$ cycling.

In this paper we include the organic nutrient pools in an analysis of the deviations of excess nitrogen stocks in the upper waters of the north Atlantic subtropical gyre and use them in combination with $\mathrm{pCFC}-12$ derived ventilation ages to estimate the production rate of total nitrogen excess and infer $\mathrm{N}_{2}$ fixation estimates in this region.

\section{TNxs: the concept}

Our aim is to identify and quantify large scale changes in the total $\mathrm{N}$ and $\mathrm{P}$ inventories that deviate from
Redfield stoichiometry. Building on the concepts of $\mathrm{N}^{*}$ and DINxs, a new variable, TNxs, is defined as: TNxs=[TN]-16[TP]=DINxs+TONxs, where TONxs=[TON $]-16[\mathrm{TOP}]$. The interpretation of TNxs is similar to that of $\mathrm{N}^{*}$ (GS97) or DINxs (H04) with the advantage of including the organic nutrient pools and being independent from differential nutrient remineralization/utilization occurring within the water column. The average value of TNxs is not expected to be zero. For example when an allochthonous constant refractory pool (e.g. a terrestrial TON pool) is introduced into the system, it will create a preformed TNxs $\neq 0$. However, one can detect a net increase/decrease of the respective $\mathrm{N}$ and $\mathrm{P}$ inventories by focusing on the deviations of actually measured from preformed organic and inorganic nutrient concentrations. Net deviations from the preformed TNxs value are expected to occur only when a net non-Redfieldian change in the total $\mathrm{N}$ and $\mathrm{P}$ inventories occurs.

\subsection{Processes contributing to DINxs and TONxs accumu-} lation - why do we need Tnxs?

The transformations and redistribution of $\mathrm{N}$ and $\mathrm{P}$ between the organic and inorganic fractions generate DINxs and TONxs anomalies, but these processes do not cause net changes in the concentrations of the total inventories (net input or removal of total nitrogen (TN) and phosphorus (TP)) and thus TNxs. Only net non-Redfieldian sources and sinks of $\mathrm{N}$ and $\mathrm{P}$ can produce TNxs anomalies. The processes that are of interest in terms of regulating DINxs, TONxs and TNxs anomalies are the following:

Negative DINxs anomalies can result from

- The remineralization of $\mathrm{P}$ rich organic matter

- The preferential remineralization of TOP to phosphate compared to the remineralisation of TON to nitrate

- The preferential uptake of $\mathrm{NO}_{3}^{-}$relative to the uptake of phosphate

- Denitrification and anammox

Positive DINxs anomalies can result from

- The remineralization of $\mathrm{N}$ rich organic matter (including that derived from $\mathrm{N}_{2}$ fixation).

- The preferential remineralization of TON to nitrate relative to the mineralization of TOP to phosphate.

- The preferential uptake of $\mathrm{PO}_{4}^{3-}$ relative to nitrate

- The deposition of low phosphate, high $\mathrm{NO}_{\mathrm{x}}+\mathrm{NH}_{3}$ material from the atmosphere

- The removal of phosphate into solid phase (e.g. apatite formation) 


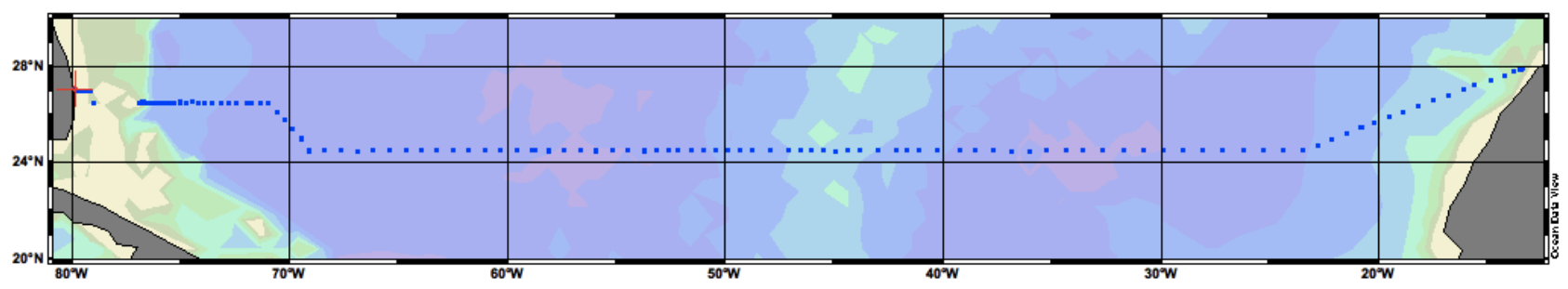

Fig. 1. Stations occupied during the cruise D279 in April-May 2004.

Negative TONxs anomalies can result from

- The production or deposition of TOP rich organic material

- The preferential remineralization of TON to nitrate compared to the remineralisation of TOP to phosphate

Positive TONxs anomalies can result from

- The production or deposition of TON rich organic material (including that derived from nitrogen fixation or atmospheric deposition).

- The preferential remineralisation of TOP to phosphate relative to TON to nitrate

Positive TNxs anomalies result from:

- The deposition of nitrogen rich material from the atmosphere

$-\mathrm{N}_{2}$ fixation

- Export of material rich in $\mathrm{P}$

Negative TNxs anomalies result from:

- Losses of fixed nitrogen (denitrification, anammox)

- Export of material rich in $\mathrm{N}$

Note that the preferential uptake of dissolved organic nutrients will transfer $\mathrm{N}$ or $\mathrm{P}$ from the dissolved into the particulate pool without any resulting change in local TONxs. It becomes clear then that imbalances in the total $\mathrm{N}$ and $\mathrm{P}$ inventories cannot be diagnosed by DINxs and TONxs alone. These need to be diagnosed by a tracer that is insensitive to organic-inorganic conversions occurring within the water column and that only reflects any net excess or deficit of $\mathrm{N}$ or $P$ relative to the expected Redfield concentrations. As long as the fraction of sinking particles that undergo differential remineralization and fall out of the area of interest $(0-1000 \mathrm{~m})$ is small, TNxs is well suited to track the net sources and sinks of fixed nitrogen occurring within the water column.

\section{Methods}

The North Atlantic subtropical gyre was surveyed along the nominal latitude of $24.5^{\circ} \mathrm{N}$ in April-May 2004 on board RRS Discovery on cruise D279 (Fig. 1). During D279, 125 full depth CTD stations were occupied. At each station up to 24 water samples were collected in Niskin bottles for the analysis of oxygen, salinity, nitrate, silicate, phosphate and total organic nutrients (TON and TOP). Samples for inorganic nutrients $\left(\mathrm{NO}_{3}^{-}+\mathrm{NO}_{2}^{-}\right.$hereafter nitrate, $\mathrm{PO}_{4}^{3-}$ hereafter phosphate) were collected from all bottles on all the CTD casts. Inorganic nutrient concentrations were measured immediately on board using a Skalar San Plus autoanalyser according to standard colorimetric techniques (Kirkwood et al., 1996). The analytical precision, based on the coefficient of variation $(\mathrm{CV})$ of duplicate samples, was $1.1 \%$ for nitrate and $0.9 \%$ for phosphate. The detection limit of the analyses, calculated as three times the noise of the baseline, was $0.1 \mathrm{mmol} \mathrm{m}^{-3}$ for nitrate and $0.01 \mathrm{mmol} \mathrm{m}^{-3}$ for phosphate. Unfiltered samples for TON and TOP analysis (which include both the dissolved and the suspended particulate organic nutrients) were carefully collected directly from Niskin bottles into $60-\mathrm{ml}$ sterile high-density polythene bottles. Sample bottles were rinsed with three times their own volume of sample and immediately frozen. Total phosphorus (TP) samples were UV oxidized in duplicates to phosphate using high intensity ultraviolet light at a wavelength below $250 \mathrm{~nm}$ in a Metrohom UV705 digester according to the method used by Sanders and Jickells (2000). Samples were subsequently analyzed for phosphate according to the standard colorimetric techniques using a Skalar San Plus autoanalyser (Kirkwood et al., 1996). The UV lamp oxidation efficiency was checked at every oxidation using an organic compound (adenosin-5monophosphatemonohydrate AMP). The average recovery of the AMP compound was $94 \%$ for P. The coefficient of variation $(\mathrm{CV})$ of the replicate samples was $7 \%$ for phosphate. TN samples were oxidized using the High Temperature Catalytic Oxidation (HTCO). This method is known to give higher recoveries as compared to the UV method (Bronk et al., 2000). HTCO was performed with a Shimadzu 5000A DOC analyser connected in series with an Antek 705E chemiluminescent nitrogen specific detector (Alvarez-Salgado and Miller, 1998). The instruments 

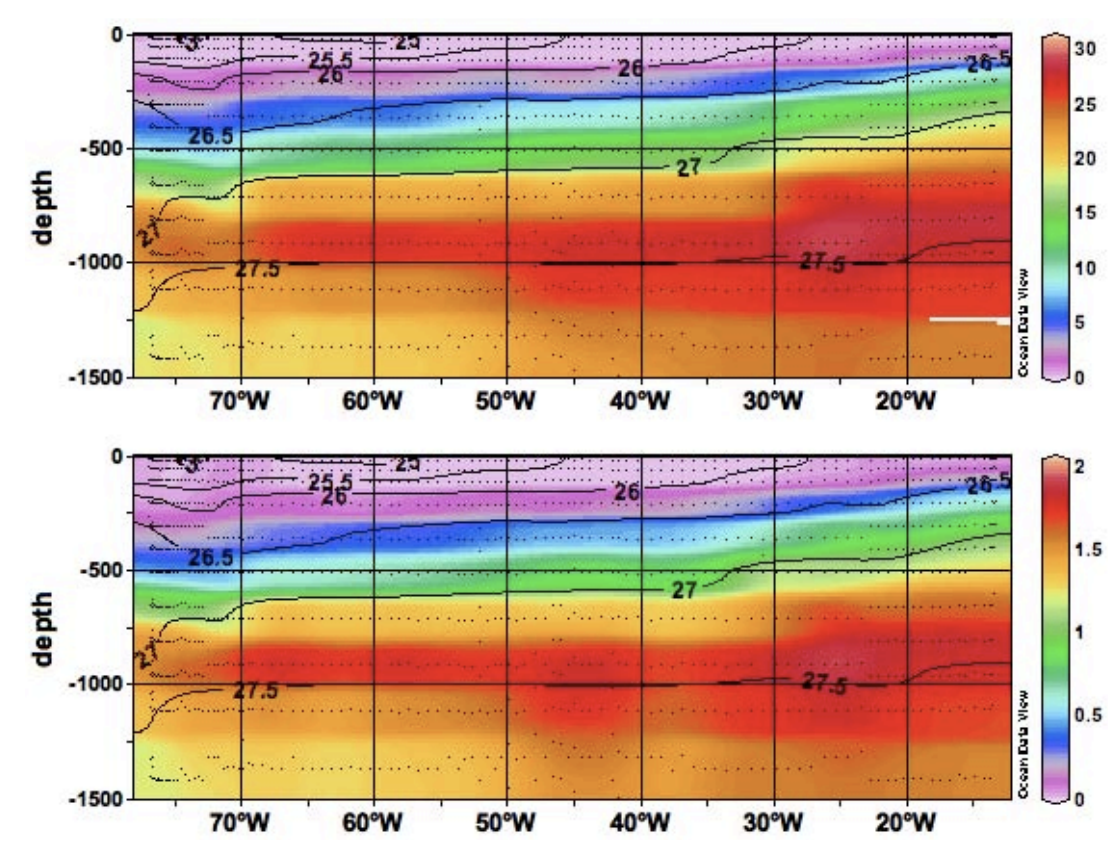

Fig. 2. Zonal $\left(24.5^{\circ} \mathrm{N}\right)$ distribution of nitrate (top) and phosphate (bottom) concentrations $\left(\mathrm{mmol} \mathrm{m}^{-3}\right)$ in the North Atlantic.

system and analytical blanks were $<1 \mathrm{mmol} \mathrm{m}^{-3}$ with a CV of $4 \%$. The instrument detection limit, estimated as three times the SD of the blank (Bronk et al., 2000), was typically $0.12 \mathrm{mmol} \mathrm{m}^{-3} \mathrm{~N}$. The oxidation efficiency was monitored using caffeine standard solutions and varied from $96 \%$ to $100 \%$. Sample concentrations were not corrected for these recovery estimates. The analytical reproducibility estimated from the CV of 4 replicate injections of the same samples was typically $2 \%$. The accuracy of the HTCO method has been determined by the use of consensus reference (CRM) materials distributed by Dr. Hansell's laboratory, University of Miami. The accuracy of $\mathrm{N}$ measurements are within 5\% of the CRM concentrations. The organic nutrient concentration, TON and TOP, are calculated by subtracting the inorganic concentration, nitrate (DIN) or phosphate (DIP) from the total TN (which also includes ammonium) and TP. Separate ammonium measurements were not carried out. As each of the measurements has an associated analytical error, TON concentration estimates have an error given by the combined uncertainty of the two analyses TN and DIN. The standard deviation of the error is thus $\mathrm{SD}_{\mathrm{TON}}=\sqrt{\left(\mathrm{SD}_{\mathrm{TDN}}^{2}+\mathrm{SD}_{\mathrm{DIN}}{ }^{2}\right)}$.

\section{Results and discussion}

4.1 Observed distributions of inorganic and organic nutrients

As expected, nitrate and phosphate concentrations increased with depth as the remineralization of organic matter occurs during particle settling (Fig. 2). Nutrient rich waters were closer to the surface on the eastern side of the subtropical gyre, generally following the sloping isopycnals. The highest concentrations of both $\mathrm{NO}_{3}^{-}$and $\mathrm{PO}_{4}^{3-}$ were found at around $1000 \mathrm{~m}$. Total organic nutrient concentrations decreased with depth suggesting a surface ocean TON and TOP source (Fig. 3). A zonal gradient of the upperocean TON concentrations occurred with the highest concentrations found in the western basin (significantly different, T test: $\alpha=0.05, P=0.056)$. TOP showed a more complex spatial variability. Low surface concentrations possibly indicate TOP utilization, a suggestion corroborated by observed high alkaline phosphatase activities (Landolfi et al., 2008 ${ }^{1}$ ). The average vertical profiles of dissolved inorganic and organic $\mathrm{N}$ and $\mathrm{P}$ are shown in Fig. 4. Nitrate and phosphate concentrations increased from the surface to $1000 \mathrm{~m}$ where the maximum concentrations reached $25.6 \pm 5.8 \mathrm{mmol} \mathrm{m}^{-3} \mathrm{NO}_{3}^{-}$and $1.60 \pm 0.52 \mathrm{mmol} \mathrm{m}^{-3} \mathrm{PO}_{4}^{3-}$ respectively. Below $1000 \mathrm{~m}$, concentrations became rather constant, both for nitrate $\left(21.0 \pm 0.4 \mathrm{mmol} \mathrm{m}^{-3}\right)$ and phosphate $\left(1.43 \pm 0.08 \mathrm{mmol} \mathrm{m}^{-3}\right)$. Average TON concentrations decreased from surface values of $4.6 \pm 1.8 \mathrm{mmol} \mathrm{m}^{-3}$ to $1.7 \pm 0.1 \mathrm{mmol} \mathrm{m}^{-3}$ at $1000 \mathrm{~m}$ and did not vary much below this depth. TOP decreased similarly from $0.11 \pm 0.11 \mathrm{mmol} \mathrm{m}^{-3}$ near the surface to almost undetectable concentrations $\left(0.03 \pm 0.01 \mathrm{mmol} \mathrm{m}^{-3}\right)$ below $1000 \mathrm{~m}$.

\footnotetext{
${ }^{1}$ Landolfi, A., Dietze, H., Mather, R., and Sanders, R.: Organic nutrients as sources of $\mathrm{N}$ and $\mathrm{P}$ to the upper layers of the North Atlantic subtropical gyre, in preparation, 2008.
} 

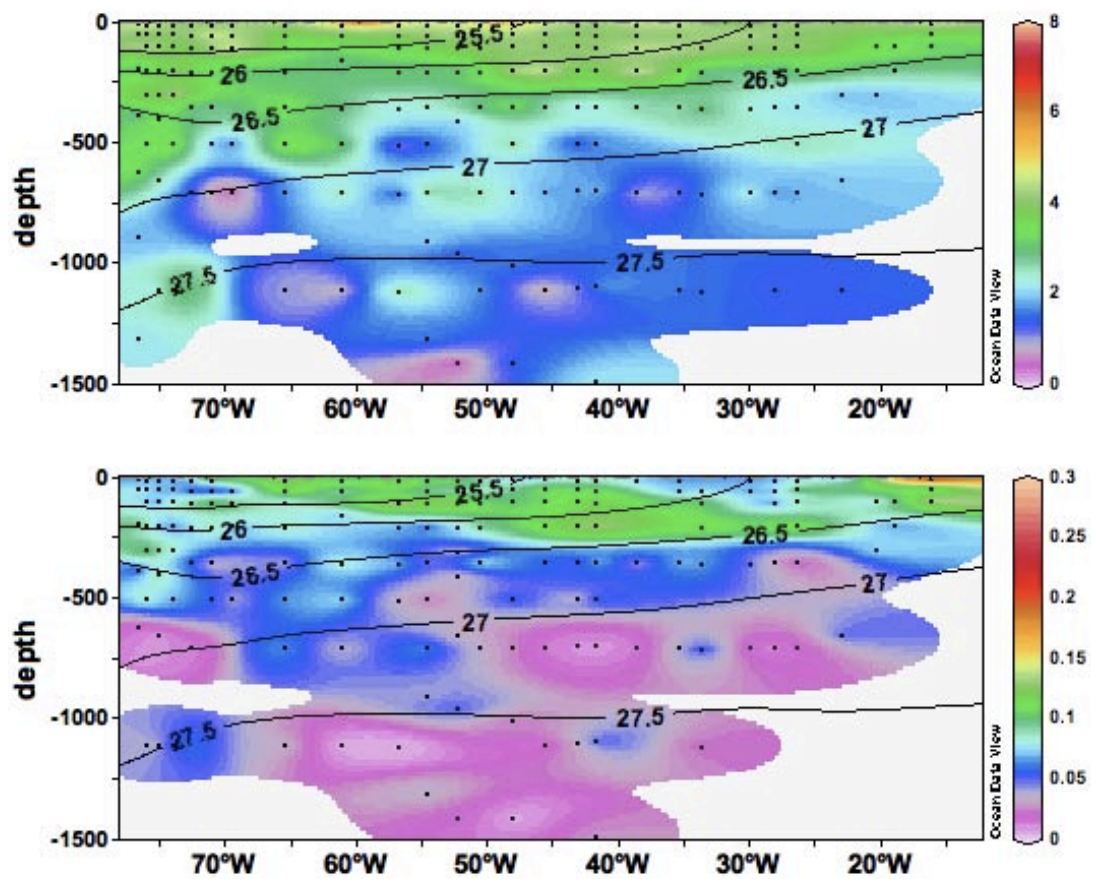

Fig. 3. Zonal $\left(24.5^{\circ} \mathrm{N}\right)$ distribution of TON (top) and TOP (bottom) concentrations $\left(\mathrm{mmol} \mathrm{m}^{-3}\right)$ in the North Atlantic.

\subsection{TNxs concentrations}

The distribution of DINxs, TONxs and TNxs anomalies as a function of longitude and depth or density are shown in Fig. 5. Positive DINxs anomalies occurred only in a limited portion of the water column between 150 and $400 \mathrm{~m}$ within the density range $\sigma_{\theta}=26-27.5$. TONxs positive anomalies were observed throughout the water column with the highest anomalies observed above $150 \mathrm{~m}$. A total positive $\mathrm{N}$ excess anomaly, TNxs, occurred in the top $1000 \mathrm{~m}$ of the entire transect. The vertical contribution of DINxs and TONxs to TNxs can be observed from the average vertical profiles (Fig. 6). In the top $150 \mathrm{~m}$ DINxs exhibited a negative anomaly possibly due to the preferential remineralization of TOP induced by the extreme P limitation of the area (Wu et al., 2000). This is, in turn, partly reflected in the positive TONxs that was on average $2.7 \pm 0.3 \mathrm{mmol} \mathrm{m}^{-3}$. In the depth layer between $150 \mathrm{~m}$ and $700 \mathrm{~m}$, TONxs decreased to $1.9 \pm 0.3 \mathrm{mmol} \mathrm{m}^{-3}$ possibly contributing about $70-80 \%$ to the concomitant increase in DINxs. Below $1000 \mathrm{~m}$, the mean TONxs concentration was $1.4 \pm 0.2 \mathrm{mmol} \mathrm{m}^{-3}$, which closely balances the deep DINxs deficit $\left(-1.4 \pm 0.3 \mathrm{mmol} \mathrm{m}^{-3}\right)$. This suggest that below $1000 \mathrm{~m}$ TONxs positve anomaly and the DINxs negative anomaly result from the residual (refractory) TON pool left by TOP preferential remineralization. From the combined contribution of DINxs and TONxs the upper $1000 \mathrm{~m}$ of the water column exhibits a positve anomaly of TNxs of $2.6 \pm 0.6 \mathrm{mmol} \mathrm{m}^{-3}$.
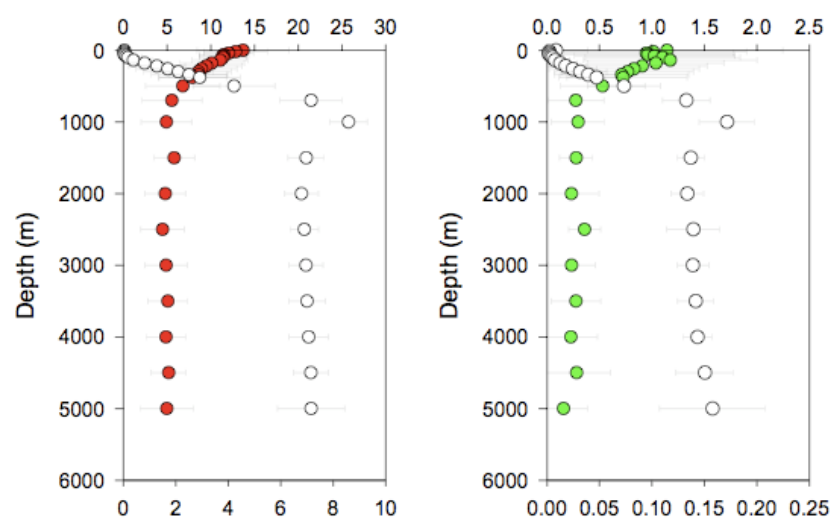

Fig. 4. Average vertical distribution of nitrate (white circles) and TON (red dots) (left) and phosphate (white circles) and TOP (green dots) (right) $\left(\mathrm{mmol} \mathrm{m}^{-3}\right)$ in the North Atlantic at $24.5^{\circ} \mathrm{N}$.

\subsection{TNxs accumulation rates}

Now we attempt to estimate rates of TNxs accumulation using several techniques. The first method we employ uses the water-column integrated TNxs standing stock combined with an age tracer. The 2nd and 3rd methods exploit the nature of water parcels that move along isopycnal surfaces to follow the rates of TNxs development on specific isopycnal surfaces. The isopycnals chosen are the ones that intercept the depths at which TNxs accumulation occurs. 

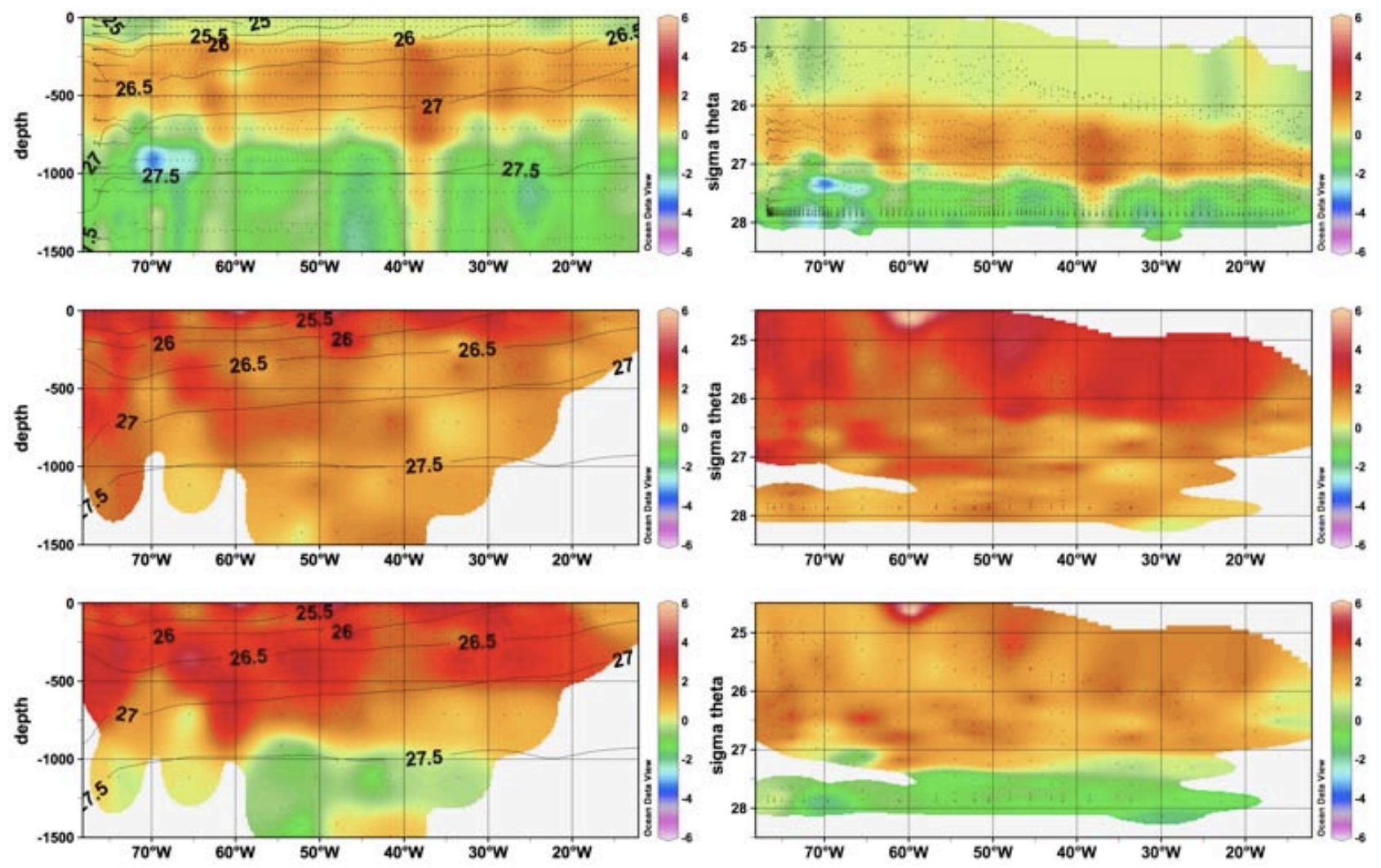

Fig. 5. Zonal $\left(24.5^{\circ} \mathrm{N}\right)$ distribution of DINxs (top), TONxs (middle) and TNxs (bottom) versus depth (left) and density (right) $\left(\mathrm{mmol} \mathrm{m}^{-3}\right.$ ) in the North Atlantic.

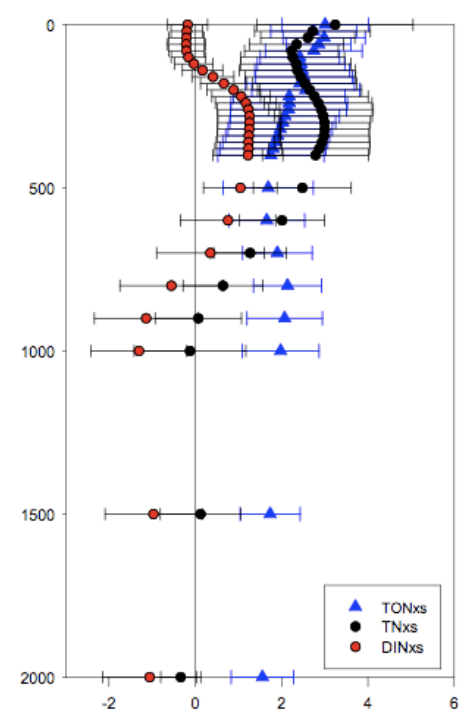

Fig. 6. Average vertical variation of DINxs, TONxs and TNxs $\left(\mathrm{mmol} \mathrm{m}{ }^{-3}\right)$ measured in the North Atlantic at $24.5^{\circ} \mathrm{N}$. Error bars represent range bars.

\subsubsection{Vertical integration}

First, we use the distribution of TNxs in combination with the pCFC-12 transient tracer distribution at each data point to infer the water-column-integrated TNxs accumulation rate. The pCFC-12 data collected during D279 has been kindly provided by Dr. Rana Fine at RSMAS/MAC, University of Miami. Here we assume a one end-member model, in which the end-member age represents the time since the water mass has been ventilated. The accumulation rate of TNxs since the water particle has left the surface is:

$$
\frac{\Delta \mathrm{TNxs}}{\Delta t}=\frac{\mathrm{TNxs}_{t}-\mathrm{TNxs}_{o}}{t_{t}-t_{o}}
$$

and the water column integrated accumulation rate is:

$$
\int_{o}^{z} \frac{\Delta \mathrm{TNxs}}{\Delta t} d z
$$

$\mathrm{TNxs}_{0}$ represents the preformed end-member $\mathrm{TNxs}$ value and $t_{o}$ is the time at which the water mass was in contact with the atmosphere. TNxs and pCFC12 age were measured at different casts and different depths http://www.biogeosciences.net/5/1199/2008/ bg-5-1199-2008-supplement.pdf. To improve the match between TNxs and pCFC-12 age data, a linear interpolation 
Table 1. Northern and Southern Component (NC, SC) end-member values of potential temperature, CFC-12 age, DIN, DIP, DINxs and TONxs on selected isopycnal surfaces 26(25.75-26.25), 26.5(26.25-26.75), 27(25.75-26.25). CFC-12 end-members values have been estimated from WOCE A16-17 sections. NC nutrients end-member values have been estimated from the Atlantic Meridional Transect (AMT 14 , spring 2004) cruise at the stations: $\sigma_{\theta} 26=18.8^{\circ} \mathrm{N}, 32.3^{\circ} \mathrm{W} ; \sigma_{\theta} 26.5=29.5^{\circ} \mathrm{N}, 35.2^{\circ} \mathrm{W} ; \sigma_{\theta} 27=42^{\circ} \mathrm{N}, 18.8^{\circ} \mathrm{W}$. SC nutrient end-member values have been estimated from the average of data points collected during cruises AMT 12,14,15 (summer 2003, spring 2004, autumn $2004)$ at specific depths from stations sampled in the area: $0-10^{\circ} \mathrm{N}, 24.99-27^{\circ} \mathrm{W}$. The number of data points $(n)$ are $n=6\left(\sigma_{\theta} 26\right) ; n=3$ $\left(\sigma_{\theta} 26.5\right) ; n=9\left(\sigma_{\theta} 27\right)$ (Torres-Valdes, personal communication).

\begin{tabular}{lcccccccc}
\hline $\begin{array}{l}\sigma_{\theta} \\
\mathrm{kg} \mathrm{m}^{-3}\end{array}$ & $\begin{array}{c}\text { Depth } \\
\mathrm{m}\end{array}$ & $\begin{array}{c}\mathrm{CFC12} \\
\text { age yr }\end{array}$ & $\begin{array}{c}\mathrm{NO}_{3} \\
\mathrm{mmolm}^{-3}\end{array}$ & $\begin{array}{c}\mathrm{PO}_{4} \\
\mathrm{mmolm}^{-3}\end{array}$ & $\begin{array}{c}\mathrm{TON} \\
\mathrm{mmolm}^{-3}\end{array}$ & $\begin{array}{c}\mathrm{TOP} \\
\mathrm{mmolm}^{-3}\end{array}$ & $\begin{array}{c}\text { DINxs } \\
\mathrm{mmolm}^{-3}\end{array}$ & $\begin{array}{c}\text { TONxs } \\
\mathrm{mmolm}^{-3}\end{array}$ \\
\hline $\mathrm{NC}$ & & & & & & & & \\
26 & 50 & $1.3 \pm 2.9$ & $0.05 \pm 0.05$ & $0.03 \pm 0.01$ & $3.96 \pm 0.20$ & $0.11 \pm 0.01$ & $-0.43 \pm 0.05$ & $2.2 \pm 0.26$ \\
26.5 & 130 & $2.7 \pm 1.0$ & $0.05 \pm 0.05$ & $0.03 \pm 0.01$ & $2.73 \pm 0.14$ & $0.01 \pm 0.01$ & $-0.25 \pm 0.05$ & $2.73 \pm 0.15$ \\
27 & 70 & $0.3 \pm 1.6$ & $1.96 \pm 0.05$ & $0.09 \pm 0.01$ & $2.86 \pm 0.14$ & $0.1 \pm 0.01$ & $0.52 \pm 0.05$ & $2.86 \pm 0.15$ \\
$\mathrm{SC}$ & & & & & & & & \\
26 & $100 \pm 6$ & $11.9 \pm 1.5$ & $21.28 \pm 5.75$ & $1.37 \pm 0.17$ & $0.62 \pm 0.17$ & $0.08 \pm 0.3$ & $-0.65 \pm 0.32$ & $-0.64 \pm 0.47$ \\
26.5 & $150 \pm 0.67$ & $13.9 \pm 1.5$ & $23.45 \pm 3.03$ & $1.48 \pm 0.17$ & $0.16 \pm 0.10$ & $0.05 \pm 0.17$ & $-0.15 \pm 0.29$ & $-0.67 \pm 0.45$ \\
27 & $250 \pm 0.5$ & $30 \pm 1.5$ & $26.49 \pm 3.20$ & $1.74 \pm 0.17$ & $1.44 \pm 0.10$ & $0.03 \pm 0.23$ & $-1.28 \pm 0.25$ & $0.96 \pm 0.34$ \\
\hline
\end{tabular}
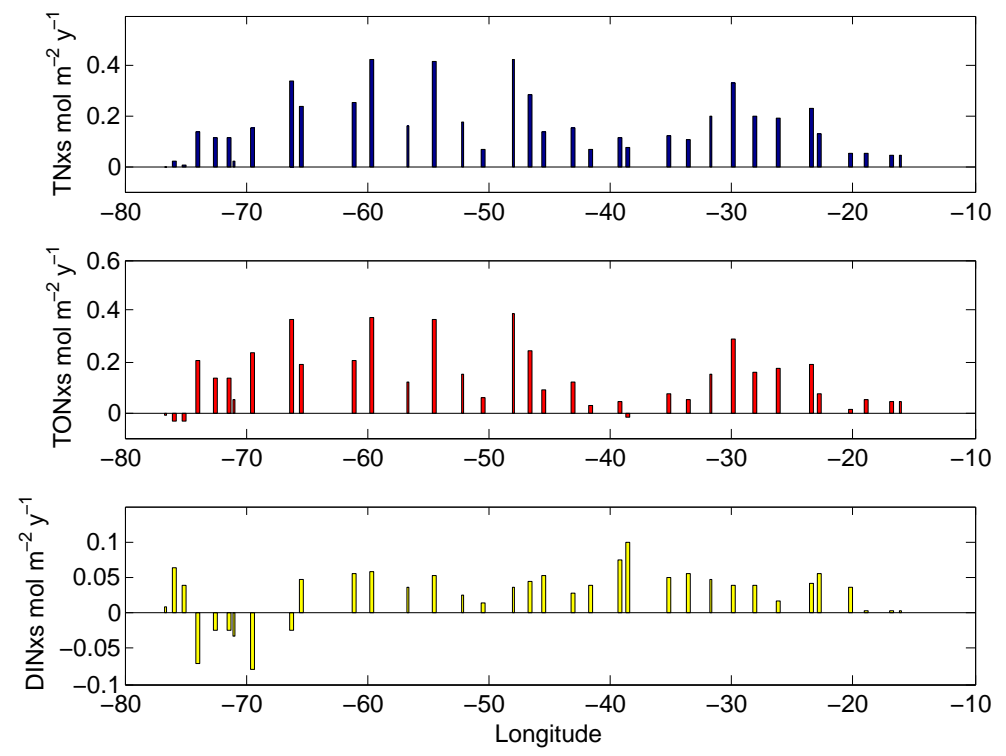

Fig. 7. Depth integrated $(1000 \mathrm{~m})$ accumulation rates of TNxs, TONxs and DINxs $\left(\mathrm{mol} \mathrm{m}^{-2} \mathrm{y}^{-1}\right)$ across the North Atlantic at $24.5^{\circ} \mathrm{N}$.

of pCFC-12 age and TNxs along a constant depth grid was carried out. Shallow $\left(\sigma_{\theta} \lesssim 26\right)$ pCFC-12 age estimates are characterized by a larger uncertainty relative to the deep thermocline, due to the decrease of atmospheric pCFC-12 after the year 2000. Also, pCFC age represents a model age for air-sea exchange processes and is not ideal for organic matter production as it is zeroed at the surface whereas organic matter, due to its biological origin, will possibly exhibit a seasonal cycle in surface waters. The northern component (NC) preformed values in the outcrop regions of 25, 26, 26.5 and 27 isopycnals (Table 1) were taken from a spring cruise (AMT12, Torres-Valdes, personal communication). As no seasonal TNxs data is available, any temporal variability of TNxs shorter than a year is difficult to constrain. Therefore, for near surface waters (pCFC-12 age $<1 \mathrm{yr}$ ) the accumulation of TNxs has been conservatively considered to occur on an annual timescale.

The $1000 \mathrm{~m}$ depth-integrated TNxs development (Fig. 7) indicates a large spatial variability $24.5^{\circ} \mathrm{N}$ ranging from -0.0013 to $0.43 \mathrm{~mol} \mathrm{~m}^{-2} \mathrm{y}^{-1}$ with the lowest integrated accumulation rates at the gyre margins and in the central region $\left(\sim 40^{\circ} \mathrm{W}\right)$. On average the $\mathrm{TNxs}$ accumulation rate was $0.16 \pm 0.12 \mathrm{~mol} \mathrm{~m}^{-2} \mathrm{y}^{-1}$. The variability of the integrated TNxs development rates may result from the spatial 

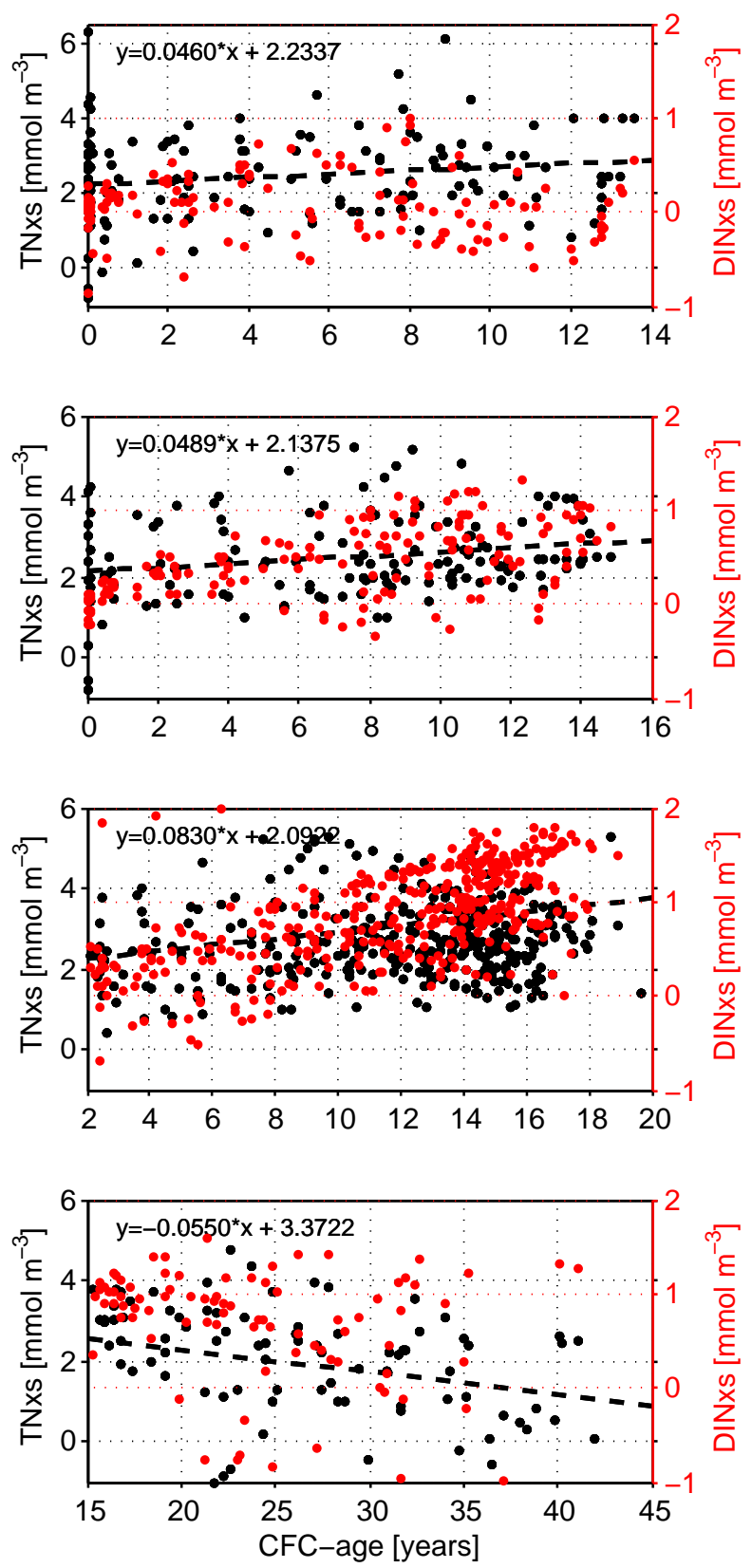

Fig. 8. Variations of DINxs (red) and TNxs (black) with pCFC-12 on density intervals $\sigma_{\theta}<25.75,25.75<\sigma_{\theta}<26.25$, $26.25<\sigma_{\theta}<26.75$ and $26.75<\sigma_{\theta}<27.25$

variability of surface biogeochemical processes that affect the accumulation of TNxs along the water parcels trajectory. Low DINxs accumulation rates west of $60^{\circ} \mathrm{W}$ indicate that DINxs accumulation rates cannot be extrapolated at basin scale as already suggested by H04. DINxs accumulation rates ranged from -0.074 (the negative sign indicates a decrease of DINxs from the original water mass) to $0.05 \mathrm{~mol} \mathrm{~m}^{-2} \mathrm{y}^{-1}$. The largest contribution to the accumulation of TNxs comes from TONxs which accumulates at an average rate of $0.13 \pm 0.10 \mathrm{~mol} \mathrm{~m}^{-2} \mathrm{y}^{-1}$.
If the total nitrogen accumulation rate is representative of the region extending from $15^{\circ} \mathrm{N}$ to $25^{\circ} \mathrm{N}$ and $25^{\circ} \mathrm{W}$ to $75^{\circ} \mathrm{W}\left(6.83 \times 10^{12} \mathrm{~m}^{2}\right)$ then the areal accumulation rate would be of the order of $1.09 \pm 0.81 \times 10^{12} \mathrm{~mol} \mathrm{y}^{-1}$ where the large range is derived from the observed large spatial variability. A caveat of this approach is the assumption of each isopycnal having uniform preformed values. In particular the farfield lateral advection of $\mathrm{N}$ rich organic matter from the tropics to the subtropical gyre is not accounted for in the preformed TNxs calculation. The lateral Ekman advection of inorganic nutrients and organic matter from the tropics into the North Atlantic subtropical gyre was computed to provide $0.047 \mathrm{~mol} \mathrm{~m}^{-2} \mathrm{y}^{-1}$ and $0.92 \mathrm{mmol} \mathrm{m}^{-2} \mathrm{y}^{-1}$ of TON and TOP (Mahaffey et al., 2004) and $0.005 \mathrm{~mol} \mathrm{~m}^{-2} \mathrm{y}^{-1}$ and $0.14 \mathrm{mmol} \mathrm{m}^{-2} \mathrm{y}^{-1}$ of nitrate and phosphate, respectively. These fluxes would cause positive TONxs and DINxs anomalies of $0.032 \mathrm{~mol} \mathrm{~m}^{-2} \mathrm{y}^{-1}$ and $0.0028 \mathrm{~mol} \mathrm{~m}^{-2} \mathrm{y}^{-1}$, respectively. Subtracting these "advective" positive anomalies in the upper $100 \mathrm{~m}$ reduces the estimate of TNxs accumulation by $\sim 20 \%$ to $0.13 \pm 0.12 \mathrm{~mol} \mathrm{~m}^{-2} \mathrm{y}^{-1}$ and the areal estimate to $8.72 \pm 8.11 \times 10^{11} \mathrm{~mol} \mathrm{y}^{-1}$. This analysis includes the contribution of TNxs accumulation in surface layers and accounts for short time-scale events (shorter then the gyre scale circulation). However, it suffers from our inability to determine the age of near-surface waters (pCFC-12 age $<1 \mathrm{yrs)}$ where $\mathrm{pCFC}$ age measurements are associated with large uncertainties. By setting the minimum age to one year we arrive at a conservative estimate of TNxs accumulation.

\subsubsection{One end-member isopycnal model - ventilation rates}

A second technique to estimate the accumulation of a tracer is to follow its gradient along isopycnal surfaces. Assuming that mixing of water masses along these isopycnals is negligible (one end-member), TNxs is expected to accumulate on each isopycnal surface with increasing age of the water on gyre-scale time-scales. Such gyre-time-scale trends, despite not being statistically significant, can be observed for TNxs on all isopycnals above $\sigma_{\theta} 26.75$ (Fig. 8). Superimposed on this mean gyre-timescale trend are "local" processes, that occur on time scales shorter than the gyre circulation. On the deepest isopycnal TNxs decreases presumably as mixing with other water masses becomes important.

Given the difficulty of objectively determining the volumes for extrapolating these isopycnal gradients to basinscale estimates (GS97, H04, H07), the total nitrogen accumulation rate has been estimated for specific isopycnals using independently estimated ventilation rates of the North Atlantic water masses. A similar approach has recently been used by Hansell et al. (2007) to investigate the excess inorganic nitrogen accumulation (DINxs). For each data point, TNxs values (DINxs+TONxs) have been corrected for their preformed concentrations (assuming only one endmember) and multiplied by the ventilation rate of the corresponding density class taken from Qiu and Huang (1995) 
Table 2. Average and maximum DINxs and TONxs accumulation in the thermocline and in surface waters. Ventilation rates have been taken from Qiu and Huang (1995).

\begin{tabular}{ccrrrr}
\hline Density & $\begin{array}{c}\text { Ventilation } \\
(\mathrm{Sv})\end{array}$ & $\begin{array}{r}\text { Mean DINxs } \\
10^{11} \mathrm{~mol} \mathrm{~N} \mathrm{y}^{-1}\end{array}$ & $\begin{array}{r}\text { Max DINxs } \\
10^{11} \mathrm{~mol} \mathrm{y} \mathrm{y}^{-1}\end{array}$ & $\begin{array}{r}\text { Mean TONxs } \\
10^{11} \mathrm{~mol} \mathrm{~N} \mathrm{y}^{-1}\end{array}$ & $\begin{array}{r}\text { Max TONxs } \\
10^{11} \mathrm{~mol} \mathrm{~N} \mathrm{y}^{-1}\end{array}$ \\
\hline$<26$ & 1.5 & $0.02 \pm 0.013$ & $0.15 \pm 0.16$ & $0.88 \pm 0.56$ & $0.87 \pm 0.55$ \\
$26-26.2$ & 2.2 & $0.43 \pm 0.28$ & $0.77 \pm 0.10$ & $0.97 \pm 0.61$ & $1.09 \pm 0.68$ \\
$26.2-26.4$ & 4 & $1.66 \pm 0.59$ & $1.94 \pm 0.35$ & $1.51 \pm 0.96$ & $1.98 \pm 1.27$ \\
$26.4-26.6$ & 3.1 & $1.30 \pm 0.46$ & $1.59 \pm 0.10$ & $0.50 \pm 1.05$ & $0.77 \pm 0.24$ \\
$26.6-26.8$ & 2.3 & $-0.02 \pm 0.29$ & $0.68 \pm 0.04$ & $-0.05 \pm 0.08$ & $-0.40 \pm 0.24$ \\
$26.8-27$ & 1.4 & $0.08 \pm 0.37$ & $0.38 \pm 0.05$ & $-0.05 \pm 0.06$ & $-0.30 \pm 0.27$ \\
$27-27.2$ & 0.6 & $-0.03 \pm 0.22$ & $0.13 \pm 0.01$ & $-0.02 \pm 0.03$ & $-0.30 \pm 0.01$ \\
Total & & $3.44 \pm 0.97$ & $5.68 \pm 0.82$ & $2.53 \pm 2.0$ & $3.70 \pm 3.26$ \\
\hline
\end{tabular}

(Table 2). Following the gyre circulation, the maximum concentrations of TNxs on these isopycnals are expected to occur near the western boundary as shown in the cartoon (Fig. 9). This westward increase can be observed for DINxs and TNxs, on the density range $26<\sigma_{\theta}<26.6$ (Fig. 10). West of $60^{\circ} \mathrm{W}$ and on deep isopycnals $\sigma_{\theta}>26.6$ mixing with low preformed DINxs southern Atlantic water masses possibly causes DINxs decrease. Summing up the contribution of all isopycnals (Table 2), the annual accumulation of TNxs is $9.38 \pm 4.18 \times 10^{11} \mathrm{~mol} \mathrm{y}^{-1}$. About $40 \%$ of this accumulation is due to organic nitrogen $\left(3.70 \pm 3.26 \times 10^{11} \mathrm{~mol} \mathrm{y}^{-1}\right)$. The low surface ventilation rates limit the importance of TONxs accumulation as compared to the estimate obtained by the vertical integration method. Overall, the two areal estimates (from the vertical integration and the one end-member model using literature ventilation rates) are in relatively good agreement. Despite the large uncertainties, this gives us some confidence regarding the size of annual production of total excess nitrogen in the North Atlantic. This areal estimate is up to 1.6 times larger than the inorganic estimate reported by Hansell et al. (2007) and would lie at the lower end of their range $\left(6.1-8.3 \times 10^{11} \mathrm{~mol} \mathrm{y}^{-1}\right)$ if only DINxs accumulation rate $\left(5.68 \pm 0.82 \times 10^{11} \mathrm{~mol} \mathrm{y}^{-1}\right)$ was considered. The scatter observed in the gradients along isopycnals (Figs. 8 and 10) is a general problem of isopycnal analyses (GS97 and H07) and may be caused by mixing with other water masses with different preformed TNxs values. For this reason a two endmember analysis might be expected to improve the estimates of the isopycnal model and will be considered next.

\subsubsection{Two end-member isopycnal mixing model}

As the third method, we now use an isopycnal two endmember mixing model following $\mathrm{H} 04$ to estimate rates of accumulation of DINxs and TONxs on specific isopycnal layers. The basic assumption is that transport occurs along isopycnal surfaces and that the mixing on any isopycnal surface can be described by a two end-member mixing model. As a water parcel is transported away from its original loca-

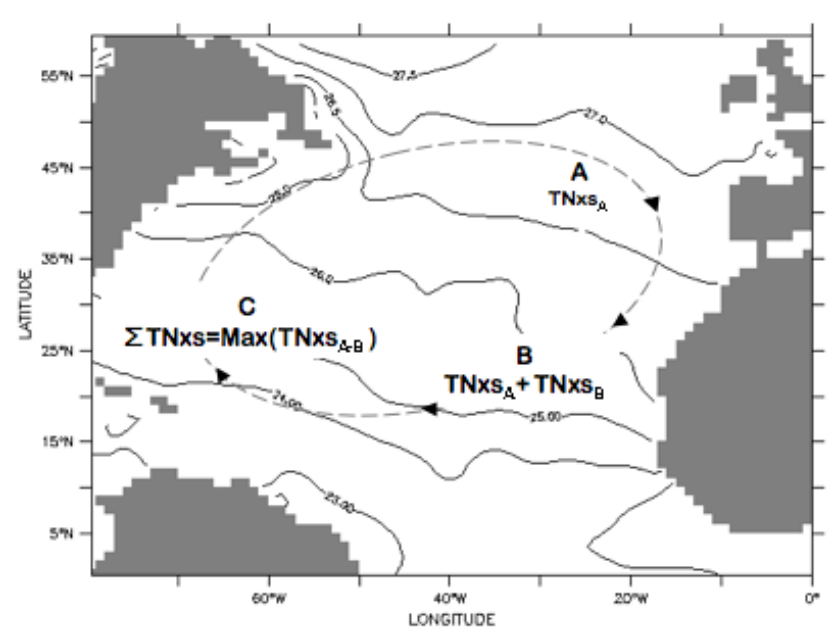

Fig. 9. Cartoon representing the build up of TNxs from the NC end member location following the gyre circulation pattern. Winter surface distribution of sigma theta from WOCE data is superimposed. Point A represents the end member location where the outcropping of $\sigma_{\theta}=26.5-27$ occurs and $\mathrm{TNxs}_{A}$ represents the end member preformed TNxs. At point B the TNxs will be given by the sum of the TNxs developed during the trajectory from point $A$ to point $B$ $\left(\mathrm{TNxs}_{B}\right)$ on that given isopycnal and the preformed TNxs $A$. At the end of the gyre circulation pattern, point $C$, the accumulated TNxs corresponds to the sum of TNxs developed among each step (A, $\mathrm{B}, \mathrm{C}$ ) and equals the maximum TNxs developed on that isopycnal. This general scheme is valid for gyre ciculation timescales but remains insensitive to short time scale build up and decrease of TNxs.

tion it loses its original properties (one end-member model) and mixes with other water masses (two end-member mixing model). This mixing can be monitored and quantified using a conservative tracer. The production or consumption of a non-conservative property can be quantified as the difference between the measured concentration and the value of the property expected if only linear mixing occurred (preformed value). This technique was used to calculate the accumulation of DINxs (H04) on specific isopycnal surfaces, 

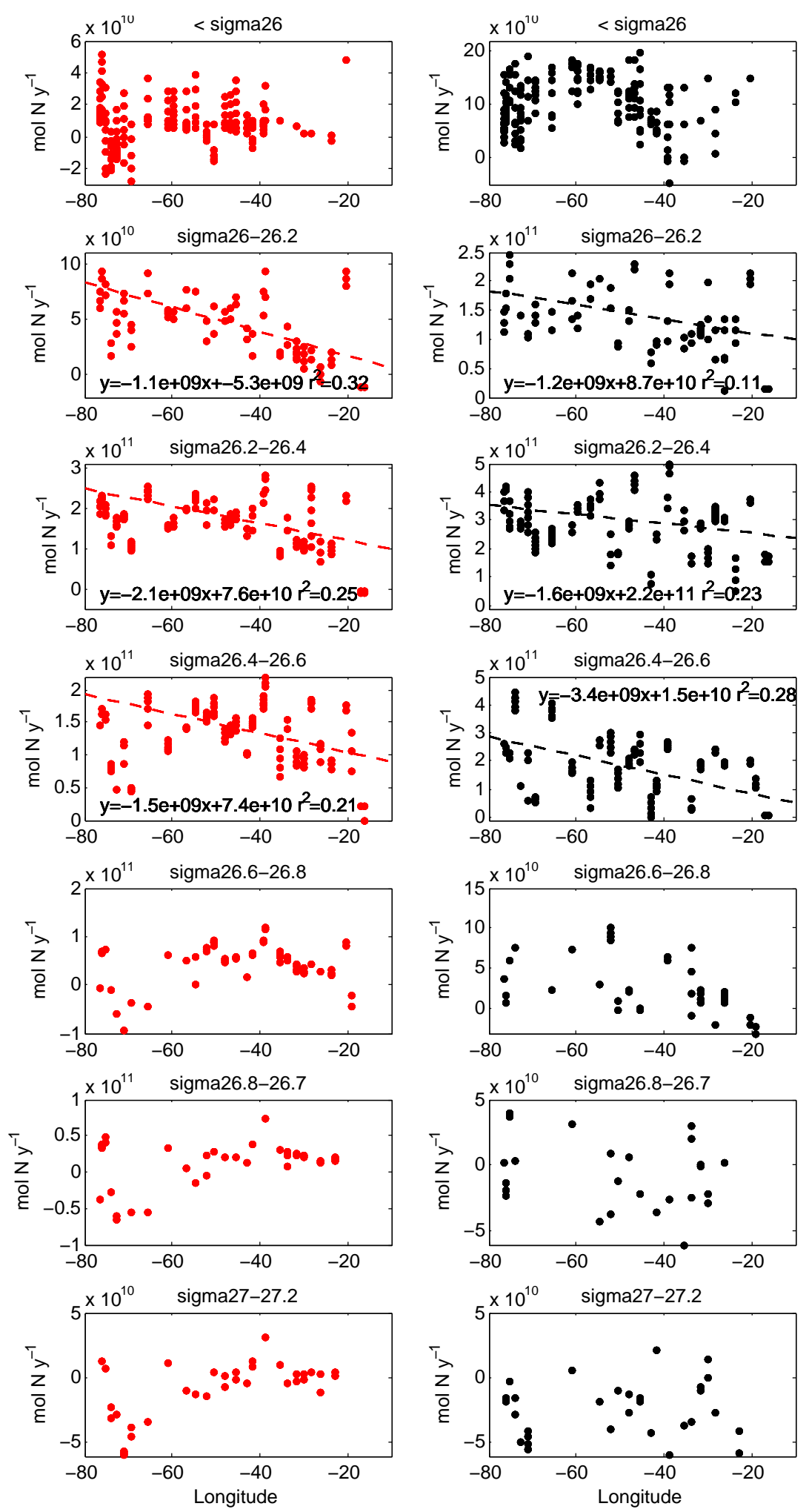

Fig. 10. Spatial variability of the areal annual DINxs (left) and TONxs (right) accumulation (mol $\mathrm{y}^{-1}$ ) on specific isopycnal layers calculated using ventilation rates from Qiu and Huang (1995). 
Table 3. Fraction of SC (F.SO) and NC (F.NO) and preformed DINxs, TONxs and pCFC-12 ages (P.DINxs, P.TONxs and P.CFC-12) along selected isopycnals at western (W) (24.5_N, 65.4_W) and eastern (E) (24.7_N, 22.8_W) locations of the subtropical gyre.

\begin{tabular}{cccrrrr}
\hline ST & $\begin{array}{c}\sigma \\
\mathrm{kg} \mathrm{m}^{-3}\end{array}$ & F.SO & F.NO & $\begin{array}{r}\text { P.DINxs } \\
\mathrm{mmol} \mathrm{m}^{-3}\end{array}$ & $\begin{array}{r}\text { P.TONxs } \\
\mathrm{mmol} \mathrm{m}^{-3}\end{array}$ & $\begin{array}{r}\text { P.CFC } \\
\text { age }\end{array}$ \\
\hline W & 26.0 & 0.15 & $0.85 \pm 0.01$ & $-0.50 \pm 0.01$ & $1.30 \pm 0.07$ & $2.8 \pm 0.88$ \\
W & 26.5 & 0.07 & $0.93 \pm 0.01$ & $-0.24 \pm 0.01$ & $2.48 \pm 0.04$ & $3.53 \pm 0.13$ \\
W & 27.0 & 0.42 & $0.54 \pm 0.02$ & $-0.3 \pm 0.03$ & $1.99 \pm 0.03$ & $11.60 \pm 0.53$ \\
E & 26.0 & 0.00 & $100 \pm 0.03$ & $-0.43 \pm 0.02$ & $2.21 \pm 0.20$ & - \\
E & 26.5 & 0.22 & $0.78 \pm 0.02$ & $-0.23 \pm 0.01$ & $1.98 \pm 0.07$ & $5.17 \pm 0.23$ \\
E & 27.0 & 0.13 & $0.87 \pm 0.17$ & $0.28 \pm 0.3$ & $2.61 \pm 0.32$ & $8.57 \pm 0.52$ \\
\hline
\end{tabular}

Table 4. Measured DINxs and TONxs along selected isopycnal surfaces at the western (W) (24.5_N, 65.4_W) and eastern (E) (24.7_N, 22.8_W) locations.

\begin{tabular}{cccrrr}
\hline ST & $\begin{array}{c}\sigma \theta \\
\mathrm{kg} \mathrm{m}^{-3}\end{array}$ & $\begin{array}{c}\text { Depth } \\
(\mathrm{m})\end{array}$ & $\begin{array}{r}\text { M. CFC-12 age } \\
(\mathrm{y})\end{array}$ & $\begin{array}{r}\text { M.DINxs } \\
\mathrm{mmol} \mathrm{m}^{-3}\end{array}$ & $\begin{array}{r}\text { M.TONxs } \\
\mathrm{mmol} \mathrm{m}^{-3}\end{array}$ \\
\hline W & 26.0 & 163 & $6.13 \pm 1.37$ & $0.64 \pm 0.034$ & $2.74 \pm 0.30$ \\
W & 26.5 & 360 & $14.78 \pm 0.61$ & $0.96 \pm 0.12$ & $1.63 \pm 0.06$ \\
W & 27.0 & 700 & $30.79 \pm 1.4$ & $-0.80 \pm 0.068$ & $3.62 \pm 0.49$ \\
E & 26.0 & 20 & - & $-0.176 \pm 0.015$ & $2.74 \pm 0.22$ \\
E & 26.5 & 200 & $11.23 \pm 0.71$ & $0.92 \pm 0.37$ & $1.51 \pm 0.08$ \\
E & 27.0 & 500 & $24.88 \pm 0.46$ & $0.7 \pm 0.02$ & $2.25 \pm 0.19$ \\
\hline
\end{tabular}

allowing for the effect of elevated $\mathrm{N}: \mathrm{P}$ ratios of organic matter released by $\mathrm{N}_{2}$ fixers.

The distribution of potential temperature, pCFC-12 ages, DINxs and TONxs on three isopycnal surfaces $\left(\sigma_{\theta}=26,26.5\right.$ and $27 \mathrm{~kg} \mathrm{~m}^{-3}$ ) are used to infer the rates of DINxs and TONxs production. The two end-member water masses used for the calculation were the northern component (NC) and the southern component (SC) described in H04. The end-member reference values for DINxs, pCFC-12 ages are listed in Table 1. Waters entering these isopycnal surfaces from the north and from the south have low preformed values of DINxs (H04) (Table 1). The subtropical gyre imports low TONxs waters from the South Atlantic (TorresValdes, personal communication) and positive TONxs from the north where ventilation of the $\sigma_{\theta}=25-27$ isopycnals occur (Table 1). Along the $24.5^{\circ} \mathrm{N}$ transect, preformed values were calculated using potential temperature as a conservative tracer following Takahashi et al. (1985):

$f a=\frac{(\theta b-\theta m)}{(\theta b-\theta a)} ; \quad f a+f b=1$

where $f a$ and $f b$ are the fractions of the two end-members, $a$ and $b$, in the mixed water region, $\theta a$ and $\theta b$ are the potential temperatures of the two end-members and $\theta m$ is the measured potential temperature. The preformed concentra- tions of DINxs were obtained for a two end member mixing model as follows:

$\mathrm{DINxs}_{\text {preformed }}=f a \mathrm{DINxs}_{a}+f b \mathrm{DINxs}_{b}$

where DINxs ${ }_{a}$ and DINxs $s_{b}$ are the preformed values of the DINxs in the $a$ an $b$ components, respectively. The same approach has been used to obtain preformed TONxs concentrations. The difference between preformed DINxs and the measured value of DINxs accounts for the accumulation of DINxs. Rates for DINxs and TONxs accumulation were computed at the western and eastern extremes of the $24.5^{\circ} \mathrm{N}$ section $\left(24.5^{\circ} \mathrm{N}, 65.4^{\circ} \mathrm{W}\right.$ and $\left.24.7^{\circ} \mathrm{N}, 22.8^{\circ} \mathrm{W}\right)$ to coincide with the beginning and the end of the gyre circulation; these sites also match the analyses made by H04. Results of the preformed values of DINxs and TONex are presented in Table 3. Measured DINxs and TONxs at the two locations are reported in Table 4. Rates of change of DINxs and TONxs were calculated from the differences between the respective preformed and measured values over the time since the water parcels left its end member location (pCFC-12 age difference) (Table 5).

On the eastern side of the gyre, the isopycnal surface $\sigma_{\theta}=26$ broadly coincided with the northern component, so no measurable ageing occurred since the water mass left the end member location. The $\sigma_{\theta}=26$ surface was deep enough (163 $\mathrm{m}$ ) to experience both DINxs and TONxs accumulation on the western side. The accumulation rates of DINxs on 
Table 5. Estimated rates of nitrogen accumulation on selected isopycnals after correction for mixing between end members. Uncertainties have been calculated with the standard equation of the error propagation of pCFC-age, preformed and measured DINxs and TONxs.

\begin{tabular}{ccrrrr}
\hline ST & $\begin{array}{c}\sigma \\
\mathrm{kg} \mathrm{m}^{-3}\end{array}$ & $\begin{array}{r}\text { D. CFC age } \\
(\mathrm{y})\end{array}$ & $\begin{array}{r}\text { Prod.R DINxs } \\
\mathrm{mmol} \mathrm{m}^{-3} \mathrm{y}^{-1}\end{array}$ & $\begin{array}{r}\text { Prod.R TONxs } \\
\mathrm{mmol} \mathrm{m}^{-3} \mathrm{y}^{-1}\end{array}$ & $\begin{array}{r}\text { Prod R. TNxs } \\
\mathrm{mmol} \mathrm{m}^{-3} \mathrm{y}^{-1}\end{array}$ \\
\hline $\mathrm{W}$ & 26.0 & $3.25 \pm 0.81$ & $0.35 \pm 0.22$ & $0.44 \pm 0.20$ & $0.79 \pm 0.30$ \\
$\mathrm{~W}$ & 26.5 & $11.25 \pm 0.31$ & $0.11 \pm 0.04$ & $-0.08 \pm 0.05$ & $0.03 \pm 0.07$ \\
$\mathrm{~W}$ & 27.0 & $19.19 \pm 0.75$ & $-0.03 \pm 0.05$ & $0.1 \pm 0.04$ & $0.07 \pm 0.06$ \\
$\mathrm{E}$ & 26.0 & - & - & - & \\
$\mathrm{E}$ & 26.5 & $6.055 \pm 0.37$ & $0.12 \pm 0.06$ & $-0.08 \pm 0.08$ & $0.04 \pm 0.10$ \\
$\mathrm{E}$ & 27.0 & $16.31 \pm 0.35$ & $0.03 \pm 0.02$ & $-0.02 \pm 0.03$ & $0.01 \pm 0.04$ \\
\hline
\end{tabular}

Table 6. Volume of isopycnal layers as reported by Hansell et al., (2004) (H04) and associated TNxs and DINxs accumulation rate $\left(\mathrm{mol} \mathrm{Ny}^{-1}\right)$. DINxs accumulation rate from $\mathrm{H} 04$ are reported for comparison.

\begin{tabular}{ccccc}
\hline Isopycnal & $\begin{array}{c}\text { Volume } \\
10^{14} \mathrm{~m}^{3}\end{array}$ & $\begin{array}{c}\text { TNxs Areal Rate } \\
10^{11} \mathrm{~mol} \mathrm{~N} \mathrm{y}^{-1}\end{array}$ & $\begin{array}{c}\text { DINxs Areal rate } \\
10^{11} \mathrm{~mol} \mathrm{~N} \mathrm{y}^{-1}\end{array}$ & $\begin{array}{c}\text { H04 DINxs Areal rate } \\
10^{11} \mathrm{~mol} \mathrm{~N} \mathrm{y}^{-1}\end{array}$ \\
\hline 26 & 1.0 & $0.79 \pm 0.30$ & $0.35 \pm 0.24$ & $0.43 \pm 0.26$ \\
26.5 & 2.6 & $0.11 \pm 0.26$ & $0.32 \pm 0.17$ & $0.24 \pm 0.13$ \\
27 & 5.1 & $0.37 \pm 0.32$ & $0.13 \pm 0.11$ & $0.20 \pm 0.13$ \\
Total & & $1.27 \pm 0.51$ & $0.80 \pm 0.36$ & $0.87 \pm 0.42$ \\
\hline
\end{tabular}

the $\sigma_{\theta}=26.5$ surface in the two regions are comparable, indicating that a two end-member model is a good approximation of water mass mixing on this isopycnal. From this analysis TONxs appears to decrease on the $\sigma_{\theta}=26.5$ isopycnal possibly contributing about $60 \%$ to the observed DINxs build up. On the deepest surface $\sigma_{\theta}=27$, the positive DINxs anomaly vanished at the western end but was still visible on the eastern side. This is consistent with the spatial extension of DINxs reported by H04. On the contrary, TONxs accumulation shows the largest rates on the western side. The rates of maximum DINxs accumulation on the three isopycnals amount to $0.50 \pm 0.23 \mathrm{mmol} \mathrm{m}^{-3} \mathrm{y}^{-1}$. This estimate is slightly lower than, but consistent with, that reported by H04 $\left(0.56 \pm 0.40 \mathrm{mmol} \mathrm{m}^{-3} \mathrm{y}^{-1}\right)$. Adding the contribution of maximum TONxs accumulation, $0.54 \pm 0.20 \mathrm{mmol} \mathrm{m}^{-3} \mathrm{y}^{-1}$, results in an increase of the total $\mathrm{N}$ excess accumulation to $1.04 \pm 0.31 \mathrm{mmol} \mathrm{m}^{-3} \mathrm{y}^{-1}$ and implies an average contribution of TONxs to TNxs of $52 \pm 37 \%$.

It is possible to estimate the areal $\mathrm{N}$ excess from the three isopycnal volumes reported in H04 (Table 6). For the area extending from $15^{\circ} \mathrm{N}$ to $25^{\circ} \mathrm{N}$ and $25^{\circ} \mathrm{W}$ to $75^{\circ} \mathrm{W}$, the net $\mathrm{N}$ excess (TNxs) amounts to $1.27 \pm 0.51 \times 10^{11} \mathrm{~mol} \mathrm{y}^{-1}$ while the inorganic nitrogen excess is $0.80 \pm 0.36 \times 10^{11} \mathrm{~mol} \mathrm{y}^{-1}$ (Table 6). The large uncertainties are the outcome of the propagation of the uncertainties of the preformed and the measured DINxs, TONxs and the pCFC-age values. As in $\mathrm{H} 04$, this estimate can be extrapolated for all isopycnal layers and can be compared with the other areal estimates reported earlier (Table 7). The two end-member mixing model yields the lowest areal rates of TNxs production of the three methods used. It should be noted, however, that given the difficulty to constrain pCFC-12 age gradients, the potential density surfaces $\sigma_{\theta}<25.75$ have been omitted from this analysis. Given the short ventilation timescales and high TONxs concentrations of the shallow isopycnals this likely leads to an underestimated contribution of the organic fraction to TNxs accumulation. Some idea of the importance of these surface isopycnals is obtained by comparing the two-end member mixing model (which excludes the shallow isopycnals) with the other two methods.

Using a two end-member mixing model has not improved the uncertainty estimate relative to the other two methods, which may be due to an inaccurate choice of the southern component end-member or to the necessity to use more than two end-members. Despite the large uncertainties and the possibility of redefining the end member choice with more data, our results indicate that the total excess $\mathrm{N}$ accumulation, which includes the contribution of TONxs, is about $\sim 100 \%$ larger than the corresponding estimate of DINxs accumulation rate (Table 7) irrespective of the method used. Each of the three methods has its uncertainty. However, the variability within the results of the three methods is smaller then the error that would be introduced if the organic nutrient components were to be ignored. We now consider the likely source of this excess nitrogen and the implications of this result on the nitrogen budget of the subtropical North Atlantic. 
Table 7. Comparison of estimates of TNxs and DINxs accumulation rates and areal rates using different methods used in this study. Areal estimates of DINxs accumulation rate from Hansell et al. (2004) $\left(^{\wedge}\right)$ and Hansell et al. (2007) $(*)$ are reported for comparison.

\begin{tabular}{ccccc}
\hline Method & Local TNxs rate & $\begin{array}{c}\text { TNxs Areal Rate } \\
10^{11} \mathrm{~mol} \mathrm{Ny}^{-1}\end{array}$ & $\begin{array}{c}\text { DINxs Areal rate } \\
10^{11} \mathrm{~mol} \mathrm{Ny}^{-1}\end{array}$ & $\begin{array}{c}\text { DINxs Areal rate } \\
10^{11} \mathrm{~mol} \mathrm{Ny}^{-1}\end{array}$ \\
\hline Vertical Integration & $0.16 \pm 0.12 \mathrm{~mol} \mathrm{~m}^{-2} \mathrm{y}^{-1}$ & $8.72 \pm 8.11$ & $0-3.4$ & - \\
One end-member model & - & $9.38 \pm 4.18$ & $5.68 \pm 0.82$ & $6.1-8.3^{*}$ \\
Two end-member model & $0.91 \pm 0.32 \mathrm{mmol} \mathrm{m}^{-3} \mathrm{y}^{-1}$ & $4.39 \pm 1.74$ & $2.75 \pm 1.25$ & $2.98 \pm 1.43^{\wedge}$ \\
\hline
\end{tabular}

\subsection{Sources of excess nitrogen}

Only non-Redfieldian processes which alter the absolute amounts of $\mathrm{N}$ and $\mathrm{P}$ can affect TNxs. To produce the positive TNxs signal observed in the North Atlantic, these processes must selectively remove $\mathrm{P}$ or selectively introduce $\mathrm{N}$.

The removal of $\mathrm{P}$ by adsorption onto mineral particles has been hypothesized to cause the extreme phosphorus limitation of the eastern Mediterranean Sea (Krom et al., 1991). Given the significant dust input from the Saharan region this process might be important in the North Atlantic. However, at present, it remains an unknown $\mathrm{P}$ sink.

Atmospheric inputs of both dry and wet deposition occur at high $\mathrm{N}: \mathrm{P}$ ratios. (Baker et al., 2003; Chen et al., 2007). Estimates of North Atlantic atmospheric deposition range from 0.017 to $0.021 \mathrm{~mol} \mathrm{Nm}^{-2} \mathrm{y}^{-1}$ (Prospero et al., 1996), with areal estimates south of $40^{\circ} \mathrm{N}$ amounting to $3 \times 10^{11} \mathrm{~mol} \mathrm{Ny}^{-1}$ (Duce et al., 1996). This deposition rate would likely induce a corresponding DINxs anomaly of $2.9 \times 10^{11} \mathrm{~mol} \mathrm{Ny}^{-1}$, i.e. 24 to $66 \%$ of the total $\mathrm{N}$ accumulation rate estimated in this study. These estimates do not include the organic nitrogen deposition, which has been reported to represent $35 \%$ of the total nitrogen atmospheric input (Cornell et al., 2003). However, the uncertainty in the atmospheric organic phosphorus deposition make a robust estimate of the contribution of atmospheric deposition to the observed build up of TONxs difficult. Here we acknowledge the possibility that it might be a non-trivial source.

The remaining TNxs signal must come from the selective production of $\mathrm{N}$ as PON, and/or DON and/or DIN. As processes that selectively introduce DIN, other than atmospheric deposition, are not known it is reasonable to think that the excess of $\mathrm{N}$ originates from the selective introduction of TON either in the form of PON or DON.

In oligotrophic waters the suspended particulate organic pool is generally considered to be less then $10 \%$ of the total organic nutrient pool (Abell et al., 2000). However, it has been suggested (Hansell et al., 2007) that Synechococcus and Prochlorococcus, which have an elevated N:P (Heldal et al., 2003) have the potential to contribute to the DINxs signal. To play a role in TNxs accumulation, these species would need to be sustained by a $\mathrm{N}$ source external to the system. Assuming that this is provided by the lateral advection of DON into the gyre the upper bound of their con- tribution can be estimated. From the reported estimates of cell abundance $\left(10^{5}\right.$ cell $\left.\mathrm{ml}^{-1}\right)$, doubling times $\left(0.5 \mathrm{~d}^{-1}\right), \mathrm{N}$ cell content $\left(\sim 9.4 \mathrm{fg} \mathrm{N}\right.$ cell $\left.^{-1}\right)$ and N:P (21-33) (Heldal et al., 2003) the excess $\mathrm{N}$ addition rate from Prochlorococcus would range from 0.19 to $0.45 \times 10^{11} \mathrm{~mol} \mathrm{Ny}^{-1}$. A similar contribution from Synechococcus is expected. From these calculations, given that it is unlikely for these species to be sustained only by advected DON, we conclude that their contribution to TNxs accumulation is small.

One candidate responsible for introducing new $\mathrm{N}$ and no equivalent of $\mathrm{P}$, is $\mathrm{N}_{2}$ fixation. Newly fixed nitrogen can enter the marine $\mathrm{N}$ pool as either PON or DON. Whatever the mechanism and the fate of this organic matter, this new $\mathrm{N}$ input will affect the TN pool following mass conservation. Given the low TONxs waters imported from the South Atlantic, $\mathrm{N}_{2}$ fixation seems the only possible explanation for the origin of the high TNxs observed in the North Atlantic. Subtracting the contribution of atmospheric deposition from the net TNxs accumulation estimated from the ventilation method and allowing for the diazotrophic N:P ratio of $40: 1$, we derive an areal $\mathrm{N}_{2}$ fixation in the order of $10.2 \pm 6.9 \times 10^{11} \mathrm{~mol} \mathrm{Ny}^{-1}$. This estimate is larger than the recent geochemical estimates of $4.3 \times 10^{11} \mathrm{~mol} \mathrm{Ny}^{-1}$ by Hansell et al. (2007), but it is consistent with direct Trichodesmium $\mathrm{N}_{2}$ fixation rates from the North Atlantic $\left(16 \times 10^{11} \mathrm{~mol} \mathrm{Ny}^{-1}\right.$, Capone et al., 2005). A modelling study by Coles and Hood (2007) also suggested high $\mathrm{N}_{2}$ fixation rate in the North Atlantic $\left(18 \times 10^{11} \mathrm{~mol} \mathrm{Ny}^{-1}\right)$. The discrepancy between $\mathrm{N}_{2}$ fixation rates reported in this study and Hansell et al. (2007) is not unexpected given the important contribution of TONxs accumulation to total $\mathrm{N}$ excess, which has been neglected previously.

\section{Conclusions}

The new geochemical tracer TNxs incorporates the contribution of organic nutrients to assess the stoichometric anomalies of the marine $\mathrm{N}$ and $\mathrm{P}$ pools. This tracer indicates that the inclusion of organic nutrients significantly increases the estimate of excess nitrogen inputs $\left(9.38 \pm 4.18 \times 10^{11} \mathrm{~mol} \mathrm{~N} \mathrm{y}^{-1}\right)$ into the North Atlantic subtropical gyre by about a factor of two. Given that the waters from the South Atlantic transferred into the North Atlantic have low TNxs values, 
the build up of this TNxs signal must be occurring in the North Atlantic. The two most likely processes responsible for this signal are atmospheric deposition and $\mathrm{N}_{2}$ fixation. The DINxs signal due to atmospheric deposition has been determined with reasonable accuracy (Baker et al., 2003). However the atmospheric organic nitrogen excess deposition to the ocean is unclear and it may be that the remainder of the TNxs signal is associated with this. Until the atmospheric deposition of the organic nutrient fraction TONxs is also defined more accurately, the best possible candidate to make up for the rest of the TNxs observed is $\mathrm{N}_{2}$ fixation. Consequently an upward estimate of $\mathrm{N}_{2}$ fixation emerges $10.2 \pm 6.9 \times 10^{11} \mathrm{~mol} \mathrm{Ny}^{-1}$. This $\mathrm{N}_{2}$ fixation estimate can reconcile the recent low geochemical estimates of $3-4 \times 10^{11} \mathrm{~mol} \mathrm{Ny}^{-1}$ by Hansell et al. (2007) and the direct estimates of $16 \times 10^{11} \mathrm{~mol} \mathrm{~N} \mathrm{y}^{-1}$ by Capone et al. (2005).

Acknowledgements. We thank R. A. Fine for providing CFC data and S. Torres-Valdes for making the nutrient AMT data available to us. Thanks to W. Koeve, H. Dietze, three anonymous reviewers and the editor for their very helpful and constructive comments on earlier versions of the manuscript. The Deutsche Forschungsgemeinschaft provided support as part of the Sonderforschungsbereich 754 .

Edited by: S. W. A. Naqvi

\section{References}

Abell, J., Emerson, S., Renaud, P.: Distributions of TOP, TON and TOC in the North Pacific subtropical gyre: Implications for nutrient supply in the surface ocean and remineralization in the upper thermocline, J. Mar. Res., 58, 203-222, 2000.

Alvarez-Salgado, X. A. and Miller, A. E. J.: Simultaneous determination of dissolved organic carbon and total dissolved nitrogen in seawater by high temperature catalytic oxidation: Conditions for precise shipboard measurements, Mar. Chem., 62, 325-333, 1998.

Baker, A. R., Kelly, S. D., Biswas, K. F., Witt, M., and Jickells, T. D.: Atmospheric deposition of nutrients to the Atlantic Ocean, Geophys. Res. Lett., 30, 2296, doi:10.1029/2003GL018518, 2003.

Bronk, D. A., Lomas, M. W., Glibert, P. M., Schukert, K. J., and Sanderson, M. P.: Total dissolved nitrogen analysis: Comparisons between the persulfate, UV and high temperature oxidation methods, Mar. Chem., 69, 163-178, 2000.

Capone, D. G., Ferrier, M. D., and Carpenter, E. J.: Amino-acid cycling in colonies of the planktonic marine cyanobacterium Trichodesmium-thiebautii, Appl. Environ. Microb., 60, 39893995, 1994.

Capone, D. G., Burns, J. A., Montoya, J. P., Subramaniam, A., Mahaffey, C., Gunderson, T., Michaels, A. F., and Carpenter, E. J.: Nitrogen fixation by Trichodesmium spp.: An important source of new nitrogen to the tropical and subtropical North Atlantic Ocean, Global Biogeochem. Cy., 19, GB2024, doi:2010.1029/2004GB002331, 2005.

Chen, Y., Mills, S., Street, J., Golan, D., Post, A., Jacobson, M., and Paytan, A.: Estimates of atmospheric dry deposition and associ- ated input of nutrients to Gulf of Aqaba seawater, J. Geophys. Res., 112, D043090, doi:10.1029/2006JD007858, 2007.

Coles, V. J. and Hood, R. R.: Modeling the impact of iron and phosphorus limitations on nitrogen fixation in the Atlantic Ocean, Biogeosciences, 4, 455-479, 2007,

http://www.biogeosciences.net/4/455/2007/.

Cornell, S. E., Jickells, T. D., Cape, J. N., Rowland, A. P., and Duce, R. A.: Organic nitrogen deposition on land and coastal environments: A review of methods and data, Atmos. Environ., 37, 2173-2191, 2003.

Deutsch, C., Gruber, N., Key, R. M., Sarmiento, J. L., and Ganachaud, A.: Denitrification and $\mathrm{N}_{2}$ fixation in the Pacific Ocean, Global Biogeochem. Cy., 15, 483-506, 2001.

Dietze, H., Oschlies, A., and Kähler, P.: Internal-wave-induced and double-diffusive nutrient fluxes to the nutrient-consuming surface layer in the oligotrophic subtropical North Atlantic, Ocean Dynam., 54, 1-7, doi:10.1007/510236-003-0060-9, 2004.

Duce, R. A., Liss, P. S., Merrill, J. T., Atlas, L. L., Buat-Menard, P., Hicks, B. B., Miller, J. M., Prospero, J. M., Arimoto, R., Church, T. M., Ellis, W., Galloway, J. N., Hansen, L., Jickells, T. D., Knap, A. H., Reinhardt, K. H., Schneider, B., Soudine, A., Tokos, J. J., Tsunogai, S., Wollast, R., and Zhou, M.: The atmospheric input of trace species to the world ocean, Global Biogeochem. Cy., 5, 193-259, 1991.

Emerson, S., Mecking, S., and Abell, J.: The biological pump in the subtropical North Pacific Ocean: Nutrient sources, redfield ratios, and recent changes, Global Biogeochem. Cy., 15, 535554, 2001.

Glibert, P. M. and Bronk, D. A.: Release of dissolved organic nitrogen by marine diazotrophic cyanobacteria, Trichodesmium spp., Appl. Environ. Microb., 60, 3996-4000, 1994.

Gruber, N. and Sarmiento, J. L.: Global patterns of marine nitrogen fixation and denitrification, Global Biogeochem. Cy., 11, 235266, 1997.

Hansell, D. A., Bates, N. R., and Olson, D. B.: Excess nitrate and nitrogen fixation in the North Atlantic Ocean, Mar. Chem., 84, 243-265, 2004.

Hansell, D. A. and Carlson, C. A.: Biogeochemestry of total organic carbon and nitrogen in the sargasso sea: control by convective overturn, Deep-Sea Res. II, 48, 1649-1667, 2001.

Hansell, D. A., Olson, D. B., Dentener, F., and Zamora, L. M.: Assesment of excess nitrate develomnet in the subtropical North Atlantic, Mar. Chem., 106, 562-579, doi:10.1016/j.marchem.20070605, 2007.

Heldal, M., Scanlan, D. J., Norland, S., Thingstad, F., and Mann, N. H.: Elemental composition of single cells of various strains of marine Prochlorococcus and Synechococcus using X-ray microanalysis, Limnol. Oceanogr., 48, 1732-1743, 2003.

Jackson, G. A. and Williams, P. M.: Importance of dissolved organic nitrogen and phosphorus to biological nutrient cycling, Deep-Sea Res., 32, 223-235, 1985.

Jenkins, W. J. and Doney, S. C.: The subtropical nutrient spiral, Global Biogeochem. Cy., 17, GB1110, doi:10.1029/2003GB002085, 2003

Jenkins, W. J. and Goldman, J. C.: Seasonal oxygen cycling and primary production in the Sargasso Sea, J. Mar. Res., 43, 465491, 1985.

Jenkins, W. J.: Nitrate flux into the euphotic zone near Bermuda, Nature, 331, 521-523, 1988. 
Karl, D., Michaels, A., Bergman, B., Capone, D., Carpenter, E., Letelier, R., Lipschultz, F., Paerl, H., Sigman, D., and Stal, L.: Dinitrogen fixation in the world's oceans, Biogeochemistry, 57, 47-98, 2002.

Karl, D. M., Letelier, R., Hebel, D. V., Bird, D. F., and Winn, C. D.: Trichodesmium blooms and new production in the North Pacifc gyre, in: Marine pelagic cyanobacteria: Trichodesmium and other diazotrophs, edited by: Carpenter, E. J., Kluwer Academic Publishers, Dordrecht, 219-237, 1992.

Kirkwood, D. S., Aminot, A., and Carlberg, S. R.: The 1994 quasimeme laboratory performance study: Nutrients in seawater and standard solutions, Mar. Pollut. Bull., 32, 640-645, 1996.

Knapp, A. N., Sigman, D. M., and Lipschultz, F.: N isotopic composition of dissolved organic nitrogen and nitrate at the Bermuda Atlantic time-series study site, Global Biogeochem. Cy., 19, GB1018, doi:1010.1029/2004GB002320, 2005.

Krom, M. D., Kress, N., Brenner, S., and Gordon, L. I.: Phosphorus limitation of primary productivity in the eastern Mediterranean Sea, Limnol. Oceanogr., 36(3), 424-432, 1991.

LaRoche, J. and Breitbarth, E.: Importance of the diazotrophs as a source of new nitrogen in the ocean, J. Sea Res., 53, 67-91, 2005.

Ledwell, J. R., Watson, A. J., and Law, C. S.: Evidence for slow mixing across the pycnocline from an open-ocean tracer-release experiment, Nature, 364, 701-703, 1993.

Mahaffey, C., Williams, R. G., Wolff, G. A., and Anderson, W. T.: Physical supply of nitrogen to phytoplankton in the Atlantic Ocean, Global Biogeochem. Cy., 18, GB1034, doi:10.1029/200368002129, 2004.

McGillicuddy, D. J., Robinson, A. R., Siegel, D. A., Jannasch, H. W., Johnson, R., Dickeys, T., McNeil, J., Michaels, A. F., and Knap, A. H.: Influence of mesoscale eddies on new production in the Sargasso Sea, Nature, 394, 263-266, 1998.

Meador, T. B., Aluwihare L. I., and Mahaffey, C.: Isotopic heterogeneity and cycling of organic nitrogen in the oligotrophic ocean, Limnol. Oceanogr., 52, 934-947, 2007.
Michaels, A. F., Olson, D., Sarmiento, J. L., Ammerman, J. W., Fanning, K., Jahnke, R., Knap, A. H., Lipschultz, F., and Prospero, J. M.: Inputs, losses and transformations of nitrogen and phosphorus in the pelagic North Atlantic ocean, Biogeochemistry, 35, 181-226, 1996.

Mulholland, M. R., Bronk, D. A., and Capone, D. G.: Dinitrogen fixation and release of ammonium and dissolved organic nitrogen by Trichodesmium IMS101, Aquat. Microb. Ecol., 37, 85-94, 2004.

Prospero, J. M., Barrett, K., Church, T., Dentener, F., Duce, R. A., Galloway, J. N., Levy, H., Moody, J., and Quinn, P.: Atmospheric deposition of nutrients to the North Atlantic basin, Biogeochemistry, 35, 27-73, 1996.

Qiu, B. and Huang, R. X.: Ventilation of the North Atlantic and North Pacific: Subduction versus obduction, J. Phys. Oceanogr., 25, 2374-2390, 1995.

Redfield, A. C., Ketchum, B. H., and Richards, F. A.: The influence of organisms on the composition of sea water, in: The sea, Vol 2, edited by: Hill, M. N., Interscience, New York, 26-77, 1963.

Reynolds, S. E., Mather, R. L., Wolff, G. A., Williams, R. G., Landolfi, A., Sanders, R., and Woodward, E. M. S.: How widespread and important is $\mathrm{N}_{2}$ fixation in the Atlantic Ocean?, Global Biogeochem. Cy., 21, GB4015, doi:10.1029/2006GB002886, 2007.

Sanders, R. and Jickells, T.: Total organic nutrients in Drake passage, Deep-Sea Res. I, 47, 997-1014, 2000.

Takahashi, T., Broecker, W. S., and Langer, S.: Redfield ratio based on chemical data from isopycnal surfaces, J. Geophys. Res., 90, 6907-6924, 1985.

Wu, J., Sund, W., Boyle, E. A., and Karl, D. M.: Phosphate depletion in the western North Atlantic Ocean, Science, 289, 759-762, 2000 . 